\title{
TRADUÇãO
}

\section{Anotações ao pensar filosófico ${ }^{1}$}

Dedicado a Herbert Marcuse em seu $70^{\circ}$ aniversário²

[§1] Ter a incumbência, como que equilibrando numa perna só, de dizer algo sobre o pensar ${ }^{3}$ filosófico e não querer resvalar na irre-

1. "Anotações ao pensar filosófico" foi lido originalmente em um programa de rádio (na Deutscblandfunk), em 1964, e publicado pela primeira vez nos Neue Deutsche Hefte em outubro de 1965 (número 17). Posteriormente foi incluído no livro Stichworte. Kritische Modelle 2, de 1969, surgido poucas semanas após a morte de Adorno, ocorrida em 6 de agosto do mesmo ano. O conjunto dos textos presentes no livro foi traduzido no Brasil sob o título Palavras e sinais. Modelos Críticos 2 (São Paulo: Vozes, 1998).

2. Christoph Gödde e Henri Lonitz, editores da correspondência entre Adorno e Horkheimer (Theodor W. Adorno/Max Horkheimer Briefwechsel, volume IV: 1950-1969, Frankfurt/Main: Suhrkamp, 2006, pp. 756-757, carta 989, de 13 de maio de 1965) informam que Adorno tinha oferecido "Anotações ao pensar filosófico" para figurar como sua contribuição em um volume de homenagem aos 70 anos de Marcuse, a serem comemorados em 19 de julho de 1968 (ver sobre isso a carta de Adorno a Horkheimer de 17 de julho de 1968, carta no. 1048, pp. 830-831). O volume estava sendo preparado por Kurt H. Wolff, Barrington Moore Jr. e Heinz Lubasz. Ao final, nenhum texto de Adorno constou do "Festschrift" para Marcuse. Na carta a Horkheimer de 13 de maio de 1965, Adorno anexou a correspondência que tinha recebido de Wolff (em 6 de maio de 1965), da qual os editores reproduzem o seguinte: "Li com a maior das expectativas, pois um ensaio do senhor sobre esse tema estaria muito bem como abertura do volume. Mas então achei que ele já estava terminado antes mesmo de ter efetivamente começado; é menos um ensaio do que, como também sugere já o título, uma nota programática, mais adequado, portanto, para uma revista do que para um volume de homenagem, para o qual contamos receber trabalhos mais acabados em lugar de apenas esboçados. Moore escreveu: 'He makes quite clear what he objects to: formalism, thought without content, specialized knowledge, and the like. I am unable to grasp at all clearly what he regards as good philosophy, and suspect that it may be un unstable mixture of everything he objects to. But he might be able to make his case if he devoted a few pages to spelling out the positive aspects of one or two philosophers whose work he does approve. Strenghtened in such fashion the essay would have the merit of presenting a viewpoint rather little known here, though Herbert's [Marcuse] whole work constitutes precisely such an effort. Leaving aside the merits of his position... I end up with doubts about whether it is possible to say anything worthwhile without discussing more substantive questions'".

3. Optamos por verter "Denken" por "pensar" e não por "pensamento", reservado para traduzir "Gedanke". É de decisiva importância no texto a dialética entre 
levância exige a limitação a um aspecto parcial. Quero, portanto, apenas compartilhar algo que acredito ter observado em meu próprio pensar, sem entrar na questão do que seja o pensar em geral ou na psicologia do pensar. Com isso, é preciso separar o pensar filosófico do pensado, do conteúdo. O que me põe em conflito com a visão penetrante e ainda não ultrapassada de Hegel do pensar filosófico. A cisão entre o que e como é pensado é, para ele, precisamente o falso, aquela má abstração que seria tarefa da filosofia corrigir com seus próprios meios. Ironicamente, a filosofia suscita tão facilmente a ira do common sense justamente porque é confundida com a abstratidade contra a qual se levanta. Decerto, tanto o conhecimento pré-filosófico como a filosofia não vão sem um quê de autonomização do pensar frente à coisa ${ }^{4}$. A ela deve o aparato lógico seu crescimento

passividade e atividade, o que se mostra não por último também no contraste entre a ação, a atividade, o processo do "pensar" e a ressonância passiva (sobre isso, ver nota vii adiante) presente em "Ge-danke", pensamento. Um dos resultados mais destacados dessa dialética é o de que a atividade do pensar filosófico deve consistir essencialmente em desbloquear a peculiar passividade que o habita.

4. Sobre o termo "Sache", vale a pena retornar à fonte hegeliana da qual parte e à qual também se contrapõe Adorno. Para tanto, é esclarecedor recorrer ao comentário de Bernard Bourgeois em sua tradução da Fenomenologia do espírito, em que distingue (com a utilização de maiúsculas e minúsculas, inclusive), "Sache" e "Ding" (lembrando ainda que Adorno examinou há pouco a "coisa em si" kantiana, que é "Ding an sich"): "A Coisa é a coisa, o assunto que interessa ou preocupa, a causa que mobiliza e requer a atenção e atividade do sujeito. A coisa (com uma minúscula), 'Ding', é simplesmente a unidade existente das propriedades sensíveis, que se dá à percepção" (Phénoménologie de l'esprit, Paris: Vrin, 2006, p. 57, nota 2). Os dois termos se reencontram, no último parágrafo do texto de Adorno, na expressão "ein unabdingbares Moment der Sache", traduzida como "momento inalienável da coisa". O adjetivo "inalienável" não consegue trazer para o português a "Ding" presente no termo "unabdingbar" (que ocorre também no $§ 4$ do texto). Uma importante diferença em relação a Hegel no que diz respeito à dialética entre "passividade" e "atividade" se mostra quando Adorno afirma que o próprio conceito de uma "Sache" é "problemático" (§ 3): contra Hegel, Adorno determina o momento da "Sache" como sendo o do "não-idêntico" (§ 5). Outra ocorrência importante se encontra no $§ 3$, na expressão "Sachlichkeit", que foi traduzida ali como "objetividade", termo que, em todas as demais ocorrências $§ \S 2,3$ e 8), traduz "Objektivität". 
desmedido face à consciência primitiva. Nela multiplicou-se, em termos de conteúdo, a força do Esclarecimento ${ }^{5}$, que marca a tendência histórica de desenvolvimento da filosofia. Mas, com sua autonomização em aparato, o pensar se tornou simultaneamente presa da reificação ${ }^{6}$, coagulou em método autocrático. Isso se manifesta de maneira brutal nas máquinas cibernéticas. Elas põem diante dos olhos das pessoas a nulidade do pensar formalizado, alheado de seu teor de coisa $^{7}$, na medida em que elas possibilitam, com vantagem sobre os sujeitos pensantes, muito daquilo de que se orgulhava o método da razão subjetiva. Se estes se tornam apaixonados órgãos executores de tal formalização, cessam virtualmente de ser sujeito. Aproximam-se das máquinas como sua cópia imperfeita. O pensar filosófico só começa onde não se satisfaz com conhecimentos que se deixam ver, nos quais não se dá a ver senão o que já lá se colocou. O sentido de dignidade humana dos computadores seria o de aliviar o pensar dos viventes de tal maneira a ganhar liberdade para o saber não implícito.

[§2] Em Kant, o pensar aparece em seu conceito mais estrito, subjetivo - sem tomar em conta, portanto, as leis objetivas de pensamento da lógica -, sob o nome da espontaneidade. O pensar seria, primeiramente, uma atividade, tal como a consciência ingênua a registra quando distingue as intuições, as impressões - que parecem reservadas ao indivíduo sem que ele tenha de se esforçar - da experi-

5. "Esclarecimento" traduz "Aufklärung", a vertente alemã das Luzes, do Iluminismo. Seguimos aqui a trilha aberta por Floriano de Sousa Fernandes ao verter o texto de Kant "Respondendo à pergunta: o que é o Esclarecimento?" (I. Kant, Textos seletos, Rio de Janeiro: Vozes, 1974). Esse foi o caminho seguido por Guido Antônio de Almeida em sua tradução do livro de Horkheimer e Adorno, Dialética do Esclarecimento. Adorno parece pressupor aqui também que quem o ouve ou lê tem algum conhecimento das teses defendidas nesse livro escrito em parceria com Horkheimer, uma obra de crescente repercussão na década de 1960 .

6. "Verdinglichung", na tradução mais comum da expressão tornada conceito por Lukács em seu História e consciência de classe. No §7 aparece "dinghaft", traduzido por "coisificado".

7. As noções de "teor de coisa" [Sachgehalt] e de "teor de verdade" [Wahrheitsgehalt] adquiriram a força conceitual reivindicada aqui por Adorno a partir do ensaio de Walter Benjamin sobre As afinidades eletivas de Goethe. As traduções propostas pretendem preservar as diferenças entre "teor" [Gehalt] e "conteúdo" [Inhalt]. 
ência do fazer que se esforça, vinculada ao pensar. A grandeza de Kant, no entanto, sua perseverança crítica, mesmo diante de suas próprias e assim chamadas posições de princípio, comprovou-se, não por último - maximamente em acordo com a situação de fato do pensar - por não ter igualado espontaneidade - que para ele é pensar - com atividade consciente. As operações decisivas, constitutivas do pensar, não eram, para Kant, o mesmo que os atos de pensar no âmbito do mundo já constituído. Sua realização dificilmente é presente para a consciência de si. A ilusão do realismo ingênuo, a visão de que, na experiência, ter-se-ia que ver com coisas em si, baseia-se - assim Kant poderia ser lido - também nisto: os atos mediante os quais a consciência forma previamente os materiais dos sentidos não lhe são conscientes enquanto tais: essa é a "profundidade" de tais atos, inteiramente passiva. Caracteriza-se, em termos imanente-sistemáticos, pelo "eu penso que tem de poder acompanhar todas as minhas representações" - a fórmula para a espontaneidade - não querer dizer mais do que: na unidade da consciência subjetiva e, mais precisamente, da consciência pessoal, encontrar-se-ia uma situação de fato; que, portanto, com todas as dificuldades que isso envolve, seria "minha" a representação, não podendo ser substituída por nenhuma outra. Ninguém pode reproduzir em sua própria imaginação a dor de um outro. Até aí alcança a apercepção transcendental. Com essa determinação, por mero pertencimento, o "eu penso" se torna já ele mesmo algo de passivo, inteiramente distinto da reflexão ativa sobre um "meu". Kant encontrou o passivo na atividade do pensar tão fielmente quanto sua imponente probidade sempre respeita o que se oferece nos fenômenos, mesmo nas proposições em que se expõe em mais alto grau; a Crítica da razão pura é já uma fenomenologia do espírito, tal como se intitulava então a análise hegeliana da consciência. Pensar, no sentido convencional de atividade, é apenas um aspecto da espontaneidade - e dificilmente o aspecto central -, localizado apenas no campo do já constituído, correlativo ao mundo das coisas. No nível que Kant estabeleceu como transcendental, atividade e passividade de modo algum se separam uma da outra de maneira administrativa, como seria de se esperar a partir da arquitetura exterior da obra. Sem que Kant o tematize, esconde-se por detrás daquele momento passivo ainda uma dependência do aparentemente independente - a apercepção originária -, frente àquele algo objetivo ainda indeterminado, que se refugia na doutrina da coisa em si para além da experiência. Nenhuma objetividade do pensar como um ato seria possível se o pensar não estivesse também 
sempre ligado, em si mesmo, segundo sua própria figura, ao que não é ele mesmo pensar: nisso há que buscar o que haveria por decifrar no pensar.

[§3] Onde o pensar é verdadeiramente produtivo, onde cria, ali ele é também um reagir. A passividade está fincada no cerne do ativo, um modelar-se do Eu no Não-Eu. Disso irradia ainda algo sobre a figura empírica do pensar filosófico. Para ser produtivo, tem de sempre estar determinado por sua coisa. Isso é sua passividade. Seu esforço coincide com sua aptidão para a passividade. A psicologia a denomina relação de objeto ou investimento de objeto. Mas essa passividade se alça para além do lado psicológico do processo do pensar. A objetividade, a verdade dos pensamentos, liga-se à sua relação com a coisa. Considerado subjetivamente, o pensar filosófico confronta incessantemente a exigência de se comportar em si de maneira lógico-consequencial, e, ainda assim, de receber em si o que ele próprio não é, e que não se submete a priori à sua legalidade própria. Como ensinaram Kant e os idealistas, o pensar como ato subjetivo tem de fato de se abandonar primeiramente à coisa ali onde a constitui ou produz. O pensar depende da coisa mesmo onde o conceito de uma coisa the é problemático, onde se empenha em instituí-la primeiramente. Dificilmente se oferece um argumento mais forte em favor da frágil - e compreensível somente na mediação recíproca de sujeito e objeto - primazia do objeto do que o de que o pensar tem de se amoldar a um objeto, mesmo se ainda não o possui de modo algum, mesmo se visa engendrá-lo. Em Kant, essa objetividade tem sua sedimentação no teor. Seu pensar está certamente direcionado para as formas do sujeito, mas procura seu alvo na determinação da objetividade. Apesar da virada copernicana - e mediante esta - Kant ratifica involuntariamente a primazia do objeto.

[§4] O pensar não se esgota no processo psicológico, tampouco na lógica atemporal pura, formal. É um modo de comportar-se do qual é inalienável a relação com aquilo para com que se comporta. ${ }^{8} \mathrm{O}$

8. Vem de longe a importância do "Verhalten" (traduzido aqui como "o comportar-se", de maneira a manter também nesse caso a forma ativa de todos os verbos substantivados, como "o pensar", "o reagir" etc) na tradição dialética moderna. Já impregnava a Fenomenologia do espirito de Hegel, que exigia um comportar-se "receptivo" em relação às diferentes maneiras como as "figuras" do espírito se dão a conhecer. No ensaio de Horkheimer "Teoria tradicional 
momento ativo do comportar-se pensante é a concentração. Esta se levanta contra o desviar da coisa. Mediante a concentração, a aplicação ${ }^{9}$ do eu é mediada por algo oposto que se lhe opõe. Inimiga do pensar é a avidez, o olhar distraído janela afora, que gostaria que nada lhe escapasse; tradições teológicas como a do Talmude já alertaram contra isso. A concentração confere ao pensar produtivo uma peculiaridade de que o priva o clichê. Deixa-se comandar - nisso não muito diferente da assim chamada iluminação artística -, contanto nada o afaste da coisa. Esta se abre à paciência como virtude do pensar. O dito "gênio é labuta" tem sua verdade não no trabalho de carroceiro, mas na paciência para com a coisa. A ressonância passiva da palavra paciência ${ }^{10}$ não expressa mal o feitio daquele modo de com-

e Teoria Crítica", trata-se antes de tudo de estabelecer os parâmetros do que seria o comportar-se "crítico", à distinção de um comportar-se meramente adaptativo ou tradicional. A dificuldade da tradução do termo está em que envolve, além da ideia de "comportar algo" e do próprio "comportar-se", elementos como "atitude", "relação" e mesmo "estado de coisas". Na abertura do penúltimo parágrafo do texto, surgirá o substantivo "Verhältnis" (traduzido como "relação"), o que impõe a necessidade de distinguir uma forma como sich verhalten zu ("comportar-se para com") da expressão Beziehung (também traduzido como "relação"), que indica "vínculo", "ligação", e que abarca, portanto, apenas um momento ou um lado do "comportar-se" e não sua dupla determinação (não por último, essa "relação de mão dupla" própria do "comportar-se" está no coração da dialética de pensar e pensado que abriu o texto). A forma "sich verhalten zu" contrasta ainda com "sich gebärden" (traduzido como "portar-se"), que aparece no início do próximo $§ 5$ e que poderia ser qualificado como um mero comportar-se, correlato, portanto de uma "relação" [Beziehung] unilateral. Note-se que há ainda uma ocorrência do termo latino "Relation" (que foi traduzido igualmente como "relação"), que está mais próximo do sentido de "Verhalten" e de "Verhältnis".

9. A "Anstrengung" [esforço] e o "sich anstrengen" [esforçar-se], que aparecem três vezes no texto, estão vinculados ao primeiro momento da dialética de "atividade" e "passividade", em que ainda se trata de fazer surgir a passividade que habita a atividade. A "Anspannung" [aplicação] surge como correlato da "concentração" [Konzentration], ou seja, surge em um momento em que se trata de descrever os contornos da figura da atividade já ciente de sua passividade e atenta para fazê-la emergir.

10. Adorno se refere aqui ao prefixo "ge-", que, na língua alemã, introduz formas passivas. Não dispomos, no português, de um prefixo com efeito semelhante. Mas ao menos a palavra "paciência" contém ressonância semelhante. 
portar-se: nem agitação laboriosa nem obstinação pertinaz, mas sim o olhar demorado e desprovido de violência sobre o objeto. A disciplina científica corrente exige do sujeito sua autodissolução em nome de uma primazia da coisa ingenuamente admitida. A filosofia a contradiz. O pensar não se pode reduzir a método, a verdade não é o resto que sobra após o extermínio do sujeito. Ele tem antes de colocar todo nervo e experiência na consideração da coisa para, idealmente, nela desaparecer. Desconfiar disso constitui a figura atual da hostilidade ao pensar. Ela se aferra ao refletir ${ }^{11}$ em sentido estrito, que se qualifica como útil graças a seu momento concentrado e passivo, e não pelo açodamento. Sua tranquilidade preserva algo da felicidade que é insuportável para a representação convencional do pensar. $\mathrm{O}$ inglês dos EUA dispõe para isso de uma expressão pejorativa própria: "arm chair thinking", o modo de comportar-se daquele que se senta confortavelmente na poltrona como um simpático e inútil vovô aposentado.

[\$5] O pérfido rancor contra aquele que se senta e pensa guarda sua execrável justificativa. Não raro tal pensar porta-se como se fosse desprovido de material. Ensimesma-se como numa esfera de suposta pureza. Hegel a denunciou como profundidade vazia. A quimera de um ser não confiscado e não desfigurado por nada de objetivo é afinal nada mais que o espelhamento em si do pensar formal e desprovido de toda determinação. Ela condena o pensar à paródia do sábio contemplando o seu umbigo; o pensar recai naquele arcaísmo em que, ao mesmo tempo em que se propõe a salvar para o pensar filosófico seu objeto específico - que por preço algum deveria ser objeto -, priva-se

11. Nachdenken é "pensar ainda mais sobre um mesmo assunto", "pensar a fundo", "pensar demoradamente". A tradução por "refletir" perde tanto a raiz "pensar" como sua determinação ulterior, a incorporação pelo "pensar" da passividade como momento essencial de sua atividade, como "concentração", caracterizada pela "aplicação". O que se perde com a tradução é muito, portanto: o fio mesmo do texto de Adorno. O "Nachdenken" é uma súmula do movimento realizado até aqui e contrasta com outros termos que podem lhe parecer à primeira vista aparentados, utilizados por Adorno em suas formas latinas: "Reflexion" [reflexão] e o "meditar" [Meditieren]. Do ponto de vista linguístico, Adorno irá se dedicar a esclarecer essa composição no penúltimo parágrafo do texto, quando diz que o "Denken" frente ao "Nachdenken" aponta para a ideia de uma "realização" [Vollzug] filosófica como uma "realização que pode ser compreendida em seus passos de execução" [Nachvollzug]. 
do momento da coisa, do não-idêntico. A sabedoria, hoje, simula uma figura agrária do espírito, historicamente irrecuperável, do mesmo naipe daquelas esculturas que imitam a originalidade enquanto praticam a imperícia primeva e com esse expediente tem esperança de alcançar a antiga verdade, que nunca existiu e que, nos dias de hoje, não vai de par senão demasiado fielmente com o mundo industrial tardio. O arcaísmo sintético do filosofar não se sairá melhor que o classicismo gípseo de Canova e Thorwaldsen frente ao classicismo ático. Mas tampouco há que transformar o refletir em um tipo de atividade prática indireta; ela serviu apenas, socialmente, ao recalque do pensar. É uma marca característica disso que, reativamente, tenham-se erigido instalações acadêmicas próprias que deveriam oferecer aos lá chamados a oportunidade para o meditar. Sem o momento contemplativo, a práxis degenera em empreendimento desprovido de conceito; meditação como esfera especial protegida, amputada da práxis possível, dificilmente se sairia melhor.

[§6] Não se descreveu ainda o refletir com suficiente precisão. Poderia ser denominado inicialmente como concentração ampliada. Enquanto visa à sua coisa, e somente ela, a concentração resguarda na coisa o que ultrapassa o previamente pensado e, com isso, faz saltar o contorno fixo da coisa. Esta, por sua vez, pode ser altamente abstrata e mediada: não se trata de prejulgar seu feitio segundo um conceito sub-reptício de concreção. O clichê do pensar como puro desenvolvimento lógico-consequencial a partir de uma posição singular merece máxima reserva. A reflexão filosófica teria de quebrar o que se espera inquebrantavelmente do pensar: o assim chamado curso do pensar. Pensamentos que são verdadeiros têm de se renovar incessantemente a partir da experiência da coisa, mesmo que esta se determine primeiramente neles. A força para tanto é a essência da consequência filosófica, não a ladainha dos silogismos. Verdade é constelação em devir, não um percurso automático em que o sujeito seria por certo aliviado, mas seria também dispensável. Que nenhum pensar filosófico de peso se deixe resumir; que não aceite a distinção científica usual entre processo e resultado - Hegel, como se sabe, representou-se a verdade como unidade de processo e resultado -, traduz em termos palpáveis tal experiência. De nada valem pensamentos filosóficos que podem ser reduzidos ao seu esqueleto ou ao seu lucro líquido. O pedantismo de incontáveis dissertações filosóficas que não fazem caso disso é mais que insuficiência estética: é índice de sua própria falsidade. O pensamento filosófico sucumbe - mesmo em textos de 
importância - onde não alcança o ideal da renovação contínua a partir da coisa. Pensar filosoficamente é como pensar intermitências, ser estorvado por aquilo que o próprio pensamento não é. No pensar enfático, os juízos analíticos - dos quais, entretanto, tem de se servir inevitavelmente - tornam-se falsos. A força do pensar de não nadar na direção da corrente é o da resistência contra o previamente pensado. O pensar enfático exige coragem cívica. O pensante singular tem que se arriscar, não pode trocar ou comprar nada sem exame; este é o cerne de experiência da doutrina da autonomia. Sem risco, sem a possibilidade presente do erro, não há objetivamente qualquer verdade. A maior parte da burrice do pensar se forma lá onde foi reprimida tal coragem, que é imanente ao pensar e que nele se agita continuamente. Burrice não é privação, a simples ausência de força para pensar, mas a cicatriz da amputação desta força. O pathos de Nietzsche sabia disso. Sua palavra de ordem, aventureira e imperialista, do viver perigosamente, no fundo era antes bem: pensar perigosamente; estimular o pensamento a partir da experiência da coisa, a não recuar diante de nada, a não se deixar obstruir por qualquer convenção do previamente pensado. Segundo sua faceta social, no entanto, a lógica consequencial autárquica tem, não por último, a função de impedir que o pensamento o faça. Não se deve provavelmente atribuir decisivamente a dotes individuais, tais como talento e inteligência, que o pensamento tenha efeito enfático, não de agitação, ali onde hoje ele tem. As razões são objetivas; uma delas, por exemplo, é a de que o pensante, favorecido por circunstâncias biográficas, não tenha deixado os mecanismos de controle expulsarem inteiramente o pensar a descoberto. A ciência necessita daquele que não a obedeceu, para o espírito deste vale o que ela difama, o memento da imbecilidade, a que ela mesma, de maneira consequente, se condena, e de que ela, preconscientemente, se envergonha.

[§7] Que, no pensar filosófico, a relação entre processo e coisa divirja qualitativamente dessa relação nas disciplinas científicas positivas, é algo que tangencia seu modo de proceder. De certa maneira, o pensar filosófico procura sempre expressar experiências; elas, por certo, não são recobertas pelo conceito empirista de experiência. Compreender filosofia significa assegurar-se daquela experiência ao refletir sobre o problema em questão de maneira autônoma e, no entanto, em estreito contato com ele. Já esperando a troça barata como reação, pode-se dizer que o pensamento filosófico é de tal feitio que, tendencialmente, obtém seus resultados antes de ser pensado. Pode-se 
desconfiar desde a base da filologia-de-hífens heideggeriana sem por isso, no entanto, se proibir de recordar que o refletir, frente ao pensar, aponta linguisticamente para a ideia de uma realização filosófica como uma realização que pode ser compreendida em seus passos de execução. Nisso reside a mais maliciosa das tentações, a da apologia, da racionalização, da justificação de convicções e opiniões cegas, previamente dadas. O thema probandum é, na mesma medida, verdade e inverdade do pensar. Desvencilha-se de sua inverdade na medida em que leve a cabo por meio da negação a tentativa de perseguir sua experiência. O pensar filosófico satisfatório é crítico não só em relação ao vigente e sua moldagem coisificada na consciência, mas, na mesma medida, contra si mesmo. Faz justiça à experiência que o anima, não mediante a codificação complacente, mas sim mediante a objetivação. Pensa filosoficamente quem corrobora a experiência espiritual naquela mesma lógica consequencial, cujo polo contrário lhe é inerente. De outro modo, a experiência espiritual permaneceria rapsódica. Só assim o refletir se torna mais do que apresentação repetente do experienciado. Como refletir crítico, sua racionalidade sobrepuja a racionalização. E, no entanto, para quem o observa em si, o pensar filosófico parece possibilitar o conhecimento daquilo que quer conhecer, na medida em que sabe ao certo apenas o que quer conhecer. Essa experiência de si do pensar contradiz a limitação kantiana de debilitar o pensar por intermédio do pensar. Ela também responde à pergunta sinistra de como se poderia pensar o que se pensa e, ainda assim, viver: por pensar. Cogito, ergo sum.

[§8] Porque a disciplina do pensar filosófico se realiza primordialmente na formulação do problema, a apresentação é, na filosofia, um momento inalienável da coisa. Também por isso, provavelmente, soluções rigorosas que ocorrem a quem pensa não irrompem como somas de uma adição operosa, depois de riscada a linha sob as parcelas. Até aí há legitimidade no idealismo. Só que este desfigura o característico do pensamento filosófico na hybris de que seria idêntico à verdade porque esta não lhe apresenta como externa. $\mathrm{O}$ que prende à filosofia, sua felicidade, está em que mesmo o pensamento desesperado carrega dentro de si algo dessa certeza do pensado, último traço da prova ontológica da existência de Deus, possivelmente o que há nela de indelével. A representação de alguém que senta e "reflete sobre algo" para descobrir o que ainda não sabia, é tão capenga quanto a contrária, a das intuições caídas do céu. O pensar sobrevém no trabalho sobre uma coisa e sobre formulações; estas zelam pelo elemento 
passivo do pensar. Dito de forma extrema: Eu não penso, e isso é já pensar. O lápis ou a caneta que se empunha ao pensar não seria um signo sensível ruim para indicar isso, tal como se diz de Simmel - ou de Husserl -, que, aparentemente, dificilmente podia pensar senão escrevendo, de maneira semelhante a alguns escritores cujos melhores pensamentos ocorrem ao escrever. Instrumentos assim, de que não se precisa fazer qualquer uso prático, advertem de que não se deve pensar de maneira desabrida, mas em algo. Por isso, textos por criticar e interpretar são apoio inestimável à objetividade do pensamento. Benjamin aludiu sobre isso certa vez com o dito de que para um pensamento respeitável é preciso uma dose respeitável de burrice. Se, por amor da quimera de sua origem, o pensamento se esquiva disso; se pressente desde logo em cada objeto o perigo da objetificação, então não se perde somente para o futuro - o que não seria objeção, quase pelo contrário -, mas deixa de ser em si certeiro. O que, entretanto, torna tanto mais decisivo quanto sejam autônomas as tarefas de que depende a fecundidade de que depende a do pensamento; que elas não sejam estabelecidas, mas se estabeleçam: limiar do pensar frente à técnica espiritual. O pensar tem que se conduzir de maneira desesperada entre essa técnica e o amador desabrido. Amadorístico é o pensar que simplesmente ignora a divisão intelectual do trabalho, em lugar de respeitá-la e de sobrepujá-la. O recomeço desprovido de malícia não emburrece menos o pensamento do que a conformação solícita à divisão do trabalho. Filosofia que, para falar com Kant, fizesse justiça a seu conceito mundano, erguer-se-ia por sobre sua concepção como ciência especial - a filosofia em seu conceito escolástico, segundo Kant, é incompatível de antemão com o conceito que lhe é próprio -, não menos do que por sobre a lenga-lenga de tipo visão de mundo, que extrai a ilusão de sua superioridade da deplorável indigência daquilo que o saber especializado, como especialidade, lhe deixou como sobra. Resistência contra o declínio da razão seria, para o pensar filosófico - sem respeito para com a autoridade estabelecida, sobretudo a das ciências humanas -, abismar-se nos teores de coisa para neles, não por sobre eles, tornar íntimo o teor de verdade. Isso seria hoje liberdade do pensar. Tornar-se-ia verdadeiro onde estivesse livre da maldição do trabalho e, em seu objeto, chegasse à quietude.

Tradução de Marcos Nobre e Adriano Januário.

Recebido em 26.03.2014

Aceito em 24.11.2014 